\title{
Floricultura y sus Medidas de Responsabilidad Social en el De- partamento de Boyacá- Colombia
}

\author{
José J. González-Millán ${ }^{1}$, Miryam T. Rodríguez-Díaz² y Oscar U. González-Millán ${ }^{3}$ \\ (1) Facultad Sede Sogamoso, Esc. Admón. Empresas, Grupo Inv. MANAGEMENT, Universidad Pedagógica \\ y Tecnológica de Colombia, Calle 4sur No 14-154, Sogamoso, Boyacá- Colombia. \\ (e-mail: javier.gonzalezmillan@uptc.edu.co) \\ (2) Facultad Ciencias Económicas, Esc. Admón. Empresas, Grupo Inv. IDEAS, Universidad Pedagógica y \\ Tecnológica de Colombia, Carretera Central del Norte Vía Paipa, Tunja, Boyacá- Colombia. \\ (e-mail: miryamteresa.rodriguez@uptc.edu.co) \\ (3) Facultad Sede Sogamoso, Esc. Ingeniería de Minas, Grupo Inv. GEAM, Universidad Pedagógica y Tec- \\ nológica de Colombia, Calle 4sur No 14-154, Sogamoso, Boyacá- Colombia \\ (e-mail: oscar.gonzalez02@uptc.edu.co)
}

Recibido Abr. 18, 2018; Aceptado Jun. 19, 2018; Versión final Jul. 25, 2018, Publicado Feb. 2019

\begin{abstract}
Resumen
El objetivo de este trabajo es la descripción y análisis de las prácticas más representativas de Responsabilidad Social Empresarial en el sector agrícola colombiano, en particular en las empresas floricultoras del Departamento de Boyacá-Colombia. Para cumplir con este objetivo, se aplicaron 212 encuestas, distribuidas proporcionalmente a los grupos de interés de las 19 empresas floricultoras objeto de estudio. En lo atingente a la metodología, el tipo de estudio fue el descriptivo-explicativo y como técnica estadística la utilizada fue el análisis descriptivo. La investigación da cuenta de una baja cultura de la Responsabilidad Social Empresarial basada en la poca importancia dada a los aspectos ambientales y clientes internos.
\end{abstract}

Palabras clave: compromiso; prácticas; empresas; grupos de interés; floricultores

\section{Floriculture and its Measurements of Social Responsibility in the Department of Boyacá-Colombia}

\begin{abstract}
The objective of the work is the description and analysis of the most representative practices of Corporate Social Responsibility in the Colombian agricultural sector, in particular in the floriculture companies of the Department of Boyacá-Colombia. To fulfill this objective, 212 surveys were applied, proportionally distributed to the Stakeholders of the 19 floriculture companies object of study. Regarding the methodology, the type of study was descriptive-explanatory and as a statistical technique, the descriptive analysis was used. The research shows a low culture of Corporate Social Responsibility based on the low importance given to environmental aspects and internal clients.
\end{abstract}

Keywords: commitment; practices; businesses; interest groups; flower growers 


\section{INTRODUCCIÓN}

La Responsabilidad Social Empresarial (RSE), es un tema que ha cobrado importancia a través de los años, puesto que ha ayudado a los grupos de interés y a las organizaciones para mejorar su reconocimiento e imagen, contribuyendo de manera positiva a la sociedad. Existen autores que relacionan el origen de la responsabilidad social con el surgimiento y evolución de las mismas organizaciones, por lo cual Witkowska (2016) lo atribuye a "la evolución del desarrollo económico y social, y se puede decir que el enfoque moderno de la RSE se remonta a la década de 1950, cuando la noción de responsabilidad social corporativa surgió". Así pues, se puede deducir que la responsabilidad social existía de manera informal en razón a que tanto la industria como la comunidad participaban en obras sociales, pero la RSE tiene auge en 1950 cuando se empieza a hablar de responsabilidad corporativa. Por otra parte algunos estudios resumen el surgimiento y evolución de la responsabilidad social así: "El análisis de la RSE surgió a Principios del Siglo XX, fue hasta la década de los 80 del Siglo XX cuando se puso de moda, con la aparición de la teoría de los grupos de interés. Ya en EI siglo XXI la RSE se ha colocado en el núcleo de la actividad de las empresas por su capacidad para "compartirlo y crear valor", ya que al crear valor para la empresa también se crea valor para la sociedad". (Porter y Kramer, citados por Hernández y Sánchez, 2016).

Para el autor antes mencionado la responsabilidad social cobra importancia a partir del momento en el que los empresarios entienden que promover acciones sociales le da un valor agregado a la organización y esta se vuelve más estimada por los clientes. En este sentido, Vallecillo y Gutiérrez (2016) explican que "la responsabilidad Social (RS), hasta ahora ha predominado su aplicación voluntaria, progresiva y mayoritaria por organizaciones del sector privado, habiéndose extendido mucho menos, podíamos decir que escasamente, al ámbito del sector público". Esta apreciación permite afirmar que la evolución la RSE se ha presentado lenta pero progresivamente en el sector privado, mientras que en la parte pública el proceso ha sido casi nulo. La responsabilidad social de alguna manera fue defiinida como parte de un compromiso legal de las compañias, por lo cual no se tenía una conciencia de la realización de acciones voluntarias, en consecuencia fue conceptualizada de la siguiente manera: "RSE se refiere a las acciones tomadas por las empresas más allá de sus obligaciones legales puramente, a contribuir a la sociedad. [...] La percepción es que los esfuerzos de recuperación deben tener lugar en una calle de dos vías: los Estados miembros deben apoyar a las empresas en conseguir a través de los tiempos difíciles, pero igualmente las empresas deben contribuir bastante a los esfuerzos de recuperación" (Lanis y Richardson, 2018)

Pero como indica el autor antes citado, la RSE es más amplia dado que no solo busca cumplir con una norma sino beneficiar a la comunidad y a la empresa misma a manera de retribución, en donde el apoyo debe ser correspondiente dando lugar a la responsabilidad social compartida. Por lo anterior y de manera amplia García et al. (2016) la definen como "el conjunto de obligaciones y compromisos, económicos, sociales, legales, medioambientales y éticos, nacionales e internacionales, de una determinada organización con sus grupos de interés". Al hacer referencia a una responsabilidad compartida se involucran todas las partes interesadas (grupos de interés), por tanto una de las mayores autoridades deja claro que la Responsabilidad Social Empresarial se entiende como todo proceso por el cual las empresas deciden contribuir al logro de una mejor sociedad y un medio ambiente más limpio. Esta responsabilidad se expresa frente a los empleados y, en general, hacia todos los interlocutores de la empresa y que a su vez pueden influir en su éxito (Commision of the European Communities, citada por Fernández et al., (2015).

Finalmente, la responsabilidad social empresarial se precisa como un grupo de actividades y procedimientos publicadas por compañías de carácter privado con el fin en primer lugar de restringir las consecuencias dañinas de las organizaciones, y como segundo factor, ayudar a la comunidad por medio de acciones que favorecen a los individuos y al ambiente (McCarthy, 2017). Ahora bien, en la actualidad la discusión acerca de la responsabilidad social según Phillips (2010); Palazzo y Schrempf-Stirling (2016) conciben que las organizaciones empresariales suelen ser consideradas en algunos casos como infractoras de derechos sociales ambientales y humanos, coincidentes con lo anterior, Padilla et. al. (2017), preceptúan que las empresas pueden impactar al medio ambiente, a la comunidad, clientes y empleados soportados en que todos estos daños son reparados con acciones sociales. La responsabilidad social ha existido y crecido a la par con las organizaciones, pero ha sido reconocida con mayor fuerza a partir de la identificación de los beneficios tanto organizacionales como sociales, de la misma manera la RSE ha sido desarrollada en gran parte por empresas privadas. En consecuencia, Peña et al. (2017) intentaron identificar los períodos por los que ha a travesado la responsabilidad social y llegaron a describirlos como aparece en la Tabla 1.

Hay tres aspectos convenientes de presentar y analizar en el contexto de este trabajo: principales vertientes de la RSE, dimensiones y enfoques de la RSE, y resoluciones de la RSE 
Tabla 1: Periodos evolutivos de la responsabilidad social (adaptada de Peña, et al., 2017)

\begin{tabular}{|l|l|}
\hline \multicolumn{1}{|c|}{ Período } & \multicolumn{1}{c|}{ Características } \\
\hline $\begin{array}{l}\text { Período incipiente de } \\
\text { RSE (1776-1900) }\end{array}$ & $\begin{array}{l}\text { Responsabilidad social: el término no se concibe formalmente, ni como un concepto aplicado } \\
\text { a la empresa, pero se entiende como una cuestión de caridad y servicio. }\end{array}$ \\
\hline $\begin{array}{l}\text { Período Filantrópico } \\
\text { de RSE (1900-1950) }\end{array}$ & $\begin{array}{l}\text { Se caracterizó por el paternalismo social, donaciones religiosas, uno de ellos llamó la } \\
\text { administración de custodia, y se convirtió en una actividad importante para las relaciones } \\
\text { públicas. }\end{array}$ \\
\hline $\begin{array}{l}\text { Período filosóficos } \\
\text { básicos de la RSE } \\
\text { (1950-1970) }\end{array}$ & $\begin{array}{l}\text { El concepto de RSE se discutió por primera vez a nivel empresarial y, en este sentido, la } \\
\text { evolución del pensamiento administrativo, nació el debate teórico entre los accionistas y } \\
\text { grupos de interés }\end{array}$ \\
\hline $\begin{array}{l}\text { Período táctica de la } \\
\text { RSE (1970-1990) }\end{array}$ & $\begin{array}{l}\text { En este período, el sector empresarial se inició para evaluar la confianza de las partes } \\
\text { interesadas para su posicionamiento, por lo que las acciones que van más allá de la ley fueron } \\
\text { vistos positivamente por la sociedad. }\end{array}$ \\
\hline $\begin{array}{l}\text { Período estratégica } \\
\text { de la RSE (1990- } \\
1999)\end{array}$ & $\begin{array}{l}\text { Su principal elemento es la nueva motivación de las empresas para seguir aplicando las } \\
\text { prácticas de RSE, inspirados en la publicación de los resultados de diversos estudios de caso } \\
\text { de negocio. }\end{array}$ \\
\hline $\begin{array}{l}\text { Periodo de RSE } \\
\text { aporte al desarrollo } \\
\text { sostenible (2000- } \\
\text { actualidad). }\end{array}$ & $\begin{array}{l}\text { RSE adquiere un papel importante debido a la participación activa de los organismos y } \\
\text { autoridades multilaterales e internacionales sobre el tema, tales como las Naciones Unidas } \\
\text { (ONU), la Unión Europea (UE), la Organización para la Cooperación y el Desarrollo Económico } \\
\text { (OCDE), la Organización Internacional del Trabajo (OIT), el Banco Mundial y el Banco } \\
\text { Interamericano de Desarrollo, entre otras instituciones. Sus acciones específicas durante este } \\
\text { período para promover una RSE que contribuye en mayor medida al desarrollo de la sociedad. }\end{array}$ \\
\hline
\end{tabular}

\section{Principales vertientes de la RSE}

Resulta claro que las diversas concepciones y vertientes que aluden a la RSE han abundado en el mundo de la literatura, más sin embargo, es coherente resaltar de manera concisa las corrientes más destacadas (aunque no son las únicas existentes como se apreciará más adelante en la Tabla 2) y los representantes de cada una de ellas, con el objeto de ampliar el contexto académico de una manera más profunda, aclarando que aunque quedarán algunos sin mencionar no es por desconocimiento sino por objetividad en su orientación temática, así las cosas, se evidencian tres grandes grupos que van desde los seminales con énfasis económico, los de corte social y filosófico y los de corte académico, sin ánimo de lucro y de percepción ética y que se referenciarán como a continuación sigue: (López y Contreras, 2010)

\section{Vertiente Económica de la RSE}

En este grupo se encuentran autores señalados como pioneros o seminales en la temática, quienes enfocaron la concepción de la responsabilidad social empresarial basados en su profesión o quehacer, pues para estos autores la RSE, no es más que un sobre costo desde el punto de vista financiero, tal como lo propone Friedman (2000), quien consideró que la verdadera responsabilidad era la de lucrarse significativamente, conservando el precepto de maximizar las ganancias, considerando que este tipo de actividades lo que llegarían a hacer era convertirse en un óbice para el crecimiento y la competitividad empresarial; otro muy destacado representante de esta corriente lo constituye Peter Drucker (2003), el cual conceptúa que la real Responsabilidad Social Empresarial es un desempeño exitoso de la organización empresarial a fin de cumplir a cabalidad su papel económico; así mismo, Carroll (1991), soporta esta línea de pensamiento afirmando que prioritariamente, el concepto se debe orientar a superar las expectativas económicas, legales, éticas y voluntarias o filantrópicas en orden de prioridades, para las cuales se debe dar un tiempo de acuerdo a su importancia en un esquema social. Por último algunos de los más actuales representantes de la corriente son Caichun et al. (2018), los cuales exponen que "quienes están en contra de la RS argumentan que los problemas sociales deben ser resueltos por el libre mercado, y que la RS no debe ser la preocupación de las empresas".

\section{Vertiente de las Ciencias sociales y Humanas de la RSE}

Esta corriente representada por diversos autores, tales como: Davis (1975) y Rodríguez (2005), quienes acentúan su concepción basados en las ciencias sociales y la filosofía; resaltando así mismo a Davidson y Griffin (2000), quienes la consideran como el conjunto de obligaciones que la empresa tiene para cuidar y promover a la sociedad en la cual se encuentra circunscrita. En esta misma línea, Schermerhorn (2002), esgrime que es un deber de la organización buscar formas de apoyo a los grupos de interés tanto internos como externos, quien soportado por Geva (2008), ponen de manifiesto que la RSE, debe propender por el interés y bienestar propio no solo de los internos sino de las partes interesadas externas generando una isostasia social donde todos salgan beneficiados en el desarrollo empresarial regional, local, nacional e incluso internacional. 


\section{Vertiente de Organizaciones académicas}

Aquí aparecen organismos internacionales como el Committe Economic Development (CED, 1971), la International Labor Organization (ILO, 2007), quienes refieren en términos generales que la RSE es claramente un conjunto de políticas y procedimientos basados en el respeto a los grupos de interés y sobre todo a la percepción ética de las organizaciones bajo todas sus manifestaciones, incluidas lógicamente las personas, las comunidades y el medio ambiente. Apuntando en esta misma dirección, Forética de España (Forética, 2008), la Comisión Económica para América Latina y el Caribe (CEPAL, 2007) y el World Bank (WB, 2007) referenciadas por Abreu y Badii (2007), reconocen a todas las partes interesadas (grupos de interés), conforme a unos valores compartidos por la organización, pues lo que está en boga es la mejor manera de hacer negocios; teniendo en cuenta las repercusiones de índole social, económico y ambiental por medio del respeto de los valores éticos, lo que conlleva a las organizaciones empresariales a realizar un comportamiento ético, sustentable y social. Soporta esta corriente adicionalmente, el Interamerican development Bank (IDB, 2007) citado por Abreu y Badii (2007), concentrando su atención en la denominada justicia social, la cual es soportada en los valores éticos y morales en pro de los clientes tanto internos como externos de una organización cualquiera que esta sea, y aclarando que no es solo lo económico y lo ambiental lo que es socialmente responsable al interior de la entidad. De acuerdo a las anteriores apreciaciones, se puede aseverar que la responsabilidad social empresarial, tiene su fundamento en el compromiso social ético y moral que tienen las compañías de hoy para con los distintos grupos de interés (que tienen que ver con ella), ya sean estos: empleados, clientes, proveedores, distribuidores, sociedad, estado, comunidades aledañas, sindicatos, propietarios y el medio ambiente; por lo tanto deben hacer a la organización sostenible y sustentable para las generaciones venideras, lo que conlleva a que este documento se oriente principalmente con esta vertiente sin dejar de lado algunos preceptos de la segunda corriente mencionada en este capítulo, por último y para dar una visión más acorde a la discusión teórica, se presenta a continuación un complemento de los diversos enfoques, expuestos en la Tabla 2, donde se amplían los enfoques que la gobiernan, sus características, filosofías, principales actores, y los objetivos básicos del enfoque.

Tabla 2: Enfoques de la Responsabilidad Social Empresarial desde la visión socioeconómica (adaptada de López y Contreras, 2010)

\begin{tabular}{|c|c|c|c|c|}
\hline $\begin{array}{l}\text { Enfoques / } \\
\text { características }\end{array}$ & Finalidad de la empresa & Objetivo de la RSE & Filosofía & $\begin{array}{l}\text { Principales } \\
\text { actores }\end{array}$ \\
\hline Macroeconómico & $\begin{array}{l}\text { Obtener beneficios } \\
\text { económicos }\end{array}$ & $\begin{array}{l}\text { La RSE no tiene } \\
\text { cabida ya que los } \\
\text { agentes son } \\
\text { racionales y amorales }\end{array}$ & $\begin{array}{l}\text { Atiende las } \\
\text { necesidades sociales e } \\
\text { implica pérdida de } \\
\text { competitividad }\end{array}$ & $\begin{array}{l}\text { La } \\
\text { responsabilidad } \\
\text { de la empresa } \\
\text { sólo es con los } \\
\text { Accionistas }\end{array}$ \\
\hline Microeconómico & $\begin{array}{l}\text { Incrementar beneficios } \\
\text { económicos a través del } \\
\text { equilibrio accionistas y } \\
\text { sociedad }\end{array}$ & $\begin{array}{l}\text { Mejorar la imagen } \\
\text { interna y externa de } \\
\text { la organización }\end{array}$ & $\begin{array}{l}\text { Realiza inversiones } \\
\text { filantrópicas hasta el } \\
\text { punto en el que sea } \\
\text { redituable (análisis } \\
\text { costo-beneficio) }\end{array}$ & $\begin{array}{l}\text { Considera a todos } \\
\text { los grupos de } \\
\text { interés (capital } \\
\text { intelectual) }\end{array}$ \\
\hline $\begin{array}{l}\text { Costos de } \\
\text { transacción }\end{array}$ & $\begin{array}{l}\text { Incrementar beneficios } \\
\text { económicos a través del } \\
\text { equilibrio entre } \\
\text { accionistas y sociedad }\end{array}$ & $\begin{array}{l}\text { Mejorar la relación } \\
\text { con los grupos de } \\
\text { interés }\end{array}$ & $\begin{array}{l}\text { La empresa debe } \\
\text { atender los asuntos } \\
\text { sociales y ambientales } \\
\text { para evitar incrementar } \\
\text { sus costos de } \\
\text { transacción }\end{array}$ & $\begin{array}{l}\text { Considera a todos } \\
\text { los grupos de } \\
\text { interés }\end{array}$ \\
\hline Administrativo & $\begin{array}{l}\text { Obtener beneficios } \\
\text { económicos tomando } \\
\text { en cuenta los intereses } \\
\text { de la sociedad }\end{array}$ & $\begin{array}{l}\text { Satisfacer las } \\
\text { demandas de la } \\
\text { sociedad para lograr } \\
\text { la continuidad de la } \\
\text { organización }\end{array}$ & $\begin{array}{l}\text { Los intereses de la } \\
\text { sociedad forman parte } \\
\text { de los objetivos de la } \\
\text { empresa }\end{array}$ & $\begin{array}{l}\text { Considera a todos } \\
\text { los grupos de } \\
\text { interés }\end{array}$ \\
\hline $\begin{array}{l}\text { Teoría de la } \\
\text { regulación }\end{array}$ & $\begin{array}{l}\text { Obtener beneficios } \\
\text { económicos sin afectar } \\
\text { a la sociedad }\end{array}$ & $\begin{array}{l}\text { Disminuir los efectos } \\
\text { negativos que la } \\
\text { empresa ha causado } \\
\text { a la sociedad }\end{array}$ & $\begin{array}{l}\text { La RSE es un elemento } \\
\text { de autorregulación }\end{array}$ & $\begin{array}{l}\text { Considera a todos } \\
\text { los grupos de } \\
\text { interés }\end{array}$ \\
\hline $\begin{array}{l}\text { Desarrollo } \\
\text { sustentable }\end{array}$ & $\begin{array}{l}\text { Obtener beneficios } \\
\text { económicos } \\
\text { asegurando la } \\
\text { sustentabilidad } \\
\text { corporativa. }\end{array}$ & $\begin{array}{l}\text { Lograr el desarrollo } \\
\text { sustentable. }\end{array}$ & $\begin{array}{l}\text { Implica aspectos } \\
\text { económicos, } \\
\text { ambientales y sociales. }\end{array}$ & $\begin{array}{l}\text { Considera a todos } \\
\text { los grupos de } \\
\text { interés. }\end{array}$ \\
\hline
\end{tabular}

Estas concepciones muestran que la RSE es el compromiso de las organizaciones con sus grupos de interés, generando bienestar social y respondiendo por los daños ocasionados a la sociedad y el medio ambiente, de tal suerte que el concepto de RSE difiere ampliamente de la Filantropia. En coherencia con lo anterior, Taquia 
(2006) declara que la RS es muy diferente a la filantropía y a la inversión social, ya que existen aspectos como la motivación, los objetivos y los resultados que hacen parte de estos términos como lo muestra la Tabla 3.

Tabla 3: Diferencias conceptuales sobre filantropía, inversión social, y RSE (adaptada de Taquía, 2006)

\begin{tabular}{|l|l|l|}
\hline \multicolumn{1}{|c|}{ Filantropía } & \multicolumn{1}{|c|}{ Inversión social } & \multicolumn{1}{c|}{$R S E$} \\
\hline Motivación: altruista & $\begin{array}{l}\text { Motivación: obtener beneficios a corto } \\
\text { plazo }\end{array}$ & $\begin{array}{l}\text { Motivación: beneficios para los trabajadores, } \\
\text { familias y comunidad }\end{array}$ \\
\hline $\begin{array}{l}\text { Impacto fuera de la } \\
\text { organización }\end{array}$ & $\begin{array}{l}\text { Impacto externo e interno (impacto en el } \\
\text { exterior pero con influencia en la empresa) }\end{array}$ & $\begin{array}{l}\text { Objetivo: lograr beneficios de mediano y largo } \\
\text { plazo }\end{array}$ \\
\hline $\begin{array}{l}\text { Produce satisfacción del } \\
\text { empresario }\end{array}$ & Mejora la imagen de la empresa & $\begin{array}{l}\text { Búsqueda de la calidad de vida de la } \\
\text { sociedad interna y externa a la empresa }\end{array}$ \\
\hline
\end{tabular}

\section{Filosofías de responsabilidad social}

En lo que tiene que ver con el concepto de RSC de Wood (1991) se reseñan a las tres filosofías de responsabilidad: la visión clásica, la visión activista limitador, y la visión gerencial (figura 1). La visión clásica se describe por el compromiso de los socios o accionistas en cuanto al reintegro de la inversión colectiva. (Silva et al., 2016); La visión activista limitador: sustenta la competencia colectiva tanto socioeconómica como de responsabilidad social. (Silva et al., 2016); y La visión gerencial se determina por el compromiso de los administradores corporativos para disminuir el riesgo de oportunidad en las conductas personales, apoyadas en la integridad de gestión y en el compromiso corporativo para la solución de los problemas sociales. (Silva et al., 2016).

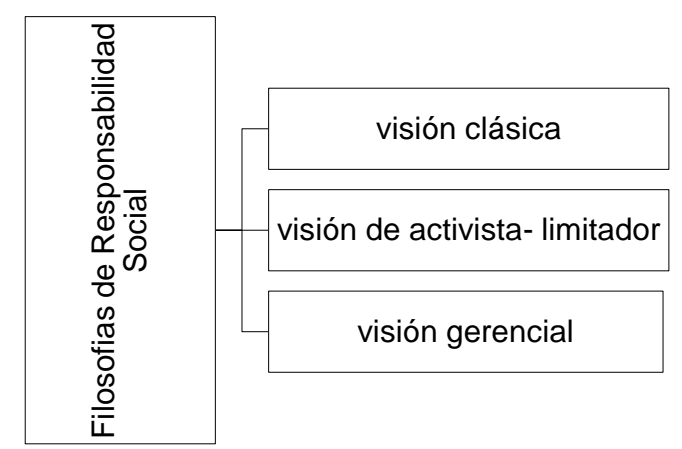

Fig. 1: Filosofías de responsabilidad (adaptada de Silva et al. 2016)

En sustento de la visión gerencial Frigant (2015) pone en consideración que "La RSE ayuda a la firma a aumentar su capacidad de combinar y fomentar nuevas competencias, con la implementación de estas prácticas puede convertirse en un vehículo para las transformaciones organizativas de las empresas", por lo cual el desarrollo de estrategias gerenciales que permiten desarrollar una responsabilidad social que benefician las comunidades aledañas e interesadas en la industria da lugar al fortalecimiento, el crecimiento y el reconocimiento organizacional.

\section{Características de responsabilidad social}

La responsabilidad social implica una inversión que a largo plazo garantiza el aumento de las utilidades de los accionistas, por lo cual la principal característica de la RSE de acuerdo a Mishra y Modi (2016) "La responsabilidad social corporativa no afecta directamente la riqueza de los accionistas, pero lo hace en presencia de capacidad de comercialización". Por lo tanto se asume que esta es una forma de mercadeo ya que le permite desarrollar programas sociales que le dan reconocimiento corporativo, lo que hace que una de las características de la responsabilidad social sea la forma de contribución, dado que en términos de Hildebrand et al. (2017) "Las empresas tienen que decidir no sólo qué elementos y cuánto desean aportar, sino también en qué forma (por ejemplo, dinero en efectivo, los productos, la compañía de conocimientos, voluntariado de los empleados)", en tal sentido es pertinente resaltar que la responsabilidad social se lleva a cabo no solo con aportes económicos sino que es posible contribuir con lo que la empresa tiene o produce. Algunos otros autores como Carnahan et al. (2017), exponen una segunda característica, expresando que "es importante tener en cuenta que la RSE puede reducir los cambios de ocupación debido a una combinación de selección y los efectos del tratamiento", sugiriendo que mediante el desarrollo de programas de RSE se motiva al personal a contribuir con las causas sociales reduciendo la posibilidad de que los trabajadores empleen su tiempo libre y sus esfuerzos en aspectos negativos, de rivalidad o mal ambiente laboral, por el contrario contribuye al crecimiento y sensibilización del talento humano. Otro aspecto diferenciador de la RSE, 
es la posibilidad de incluir y hacer tanto partícipes como beneficiarias a todas las partes interesadas, así mismo la compañía se expone a que cada parte interprete el desarrollo de los programas sociales a favor o en contra de la organización.

Las interpretaciones antes mencionadas son una ventaja importante para las empresas puesto que considera que, "Una firma con la RSE tiene que satisfacer a todas las partes interesadas, incluidos los accionistas, empleados, clientes, proveedores, sociedades, etc. Mientras que algunas empresas responden a esta tendencia dedicando más recursos en la RSE, otros todavía sostienen que las inversiones adicionales en materia de RSE son incompatibles con maximización de los beneficios y el potencial problema de agencia unidad" (Chang et al., 2018). Así, la relación entre una empresa rendimiento y el grado de compromiso de RSE sigue beneficios y el potencial problema de agencia unidad.

\section{Tipos de responsabilidad social empresarial}

En este aspecto es necesario resaltar que la responsabilidad social empresarial (RSE) es conceptualizada como las tareas de la empresa que surgen para mejorar o facilitar el desarrollo de un programa social independientemente de los beneficios inminentes de la compañía y sus asociados [...] junto con la inclusión de variados grupos de interés a partir de los cuales se puede identificar una responsabilidad social empresarial de tipo interna y externa (Farooq et al., 2017). (Figura 2)

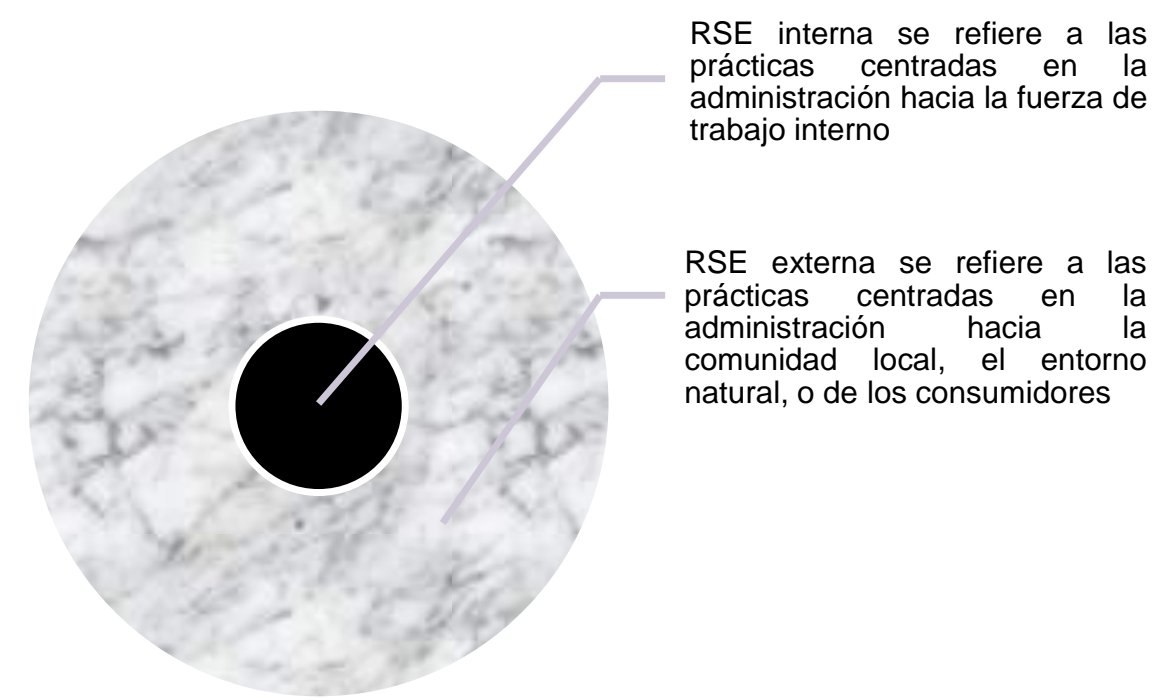

Fig. 2: Responsabilidad social interna y externa (adaptada de Farooq et al., 2017)

La responsabilidad social empresarial interna se enfoca a las actividades promovidas desde la gerencia hacia los empleados y socios y de otro lado la externa hace referencia a las tareas dirigidas a la comunidad y clientes, por lo que lo ideal es que la organización pueda desarrollar programas sociales al interior y en el entorno con el propósito de mantener satisfechas a todas las partes de la compañía.

\section{Multidimensiones de responsabilidad social}

En la Tabla 4, se puede apreciar las tres dimensiones de la responsabilidad social, expresadas por Preuss et al., (2016). Desde el punto de vista estratégico y de gestión del conocimiento la RSE es vista como una de sus dimensiones que complementa la gestión de la gerencia en cuanto al bienestar de sus partes interesadas, en este aspecto, Bhimani y Soonawalla (citados por Mohd et al., 2017), afirman que "La RSE es una de las dimensiones del CG, incluyendo estructura directiva, liderazgo estratégico, la administración, la estructura de capital y de las relaciones de mercado, el modelo insiste en que una organización sea responsable ante la sociedad y comunidad (dimensión externa de la RSC), por un lado, y para los empleados en el otro (dimensión interna de la RSE) presentan otro punto de vista de la relación CG y RSE".

Finalmente se espera que las organizaciones desarrollen una dimensión que aunque está inmersa en la definición de responsabilidad social pocos se apoderan de ella, en términos de Freeman y Reed, citado por Chang et al. (2018) "se hace referencia a la voluntariedad y la orientación de las partes". Puesto que no todas las organizaciones desarrollan ideas y promueven actividades sociales pensadas netamente en el beneficio de la comunidad sino que siempre está en doble vía, es decir la organización espera algo a cambio de dichas contribuciones. Por el contrario según Baraibar y Luna (2018) "La importancia de la responsabilidad social empresarial (RSE) se deriva del interés de la empresa para integrar las cuestiones sociales con el fin de garantizar el desarrollo sostenible". 
Tabla 4: Dimensiones de la responsabilidad social (adaptada de Preuss et al., 2016)

\begin{tabular}{|c|c|}
\hline Dimensión & Descripción \\
\hline $\begin{array}{l}\text { El comportamiento controvertido que las } \\
\text { empresas exigen a sus empleados para } \\
\text { evitar la participación en el soborno. }\end{array}$ & $\begin{array}{l}\text { Estos deberían aplicarse dependiendo del contexto, por ejemplo cuando } \\
\text { se comparan organizaciones en cuanto a responsabilidad social en el } \\
\text { ámbito nacional e internacional }\end{array}$ \\
\hline $\begin{array}{l}\text { Los compromisos corporativos para la } \\
\text { sociedad. }\end{array}$ & $\begin{array}{l}\text { Aunque la responsabilidad social maneja un lenguaje universal para ser } \\
\text { comparadas las organizaciones de diferentes países el propósito } \\
\text { fundamental es el de responder a las necesidades de la comunidad. }\end{array}$ \\
\hline $\begin{array}{l}\text { Los principios y valores éticos que las } \\
\text { empresas se comprometen a respetar. }\end{array}$ & $\begin{array}{l}\text { Esta es una de las dimensiones más profunda y es la más difícil de cumplir } \\
\text { debido a los cambios y presiones sociales existentes en el interior del ser. }\end{array}$ \\
\hline
\end{tabular}

\section{Dimensiones y enfoques de la rse}

Una de las teorías más representativas de la RSE es la de Caroll. La teoría de Caroll (1999), punto de partida de varios otros modelos (Quazy y O'Brien, 2000), construye un interesante modelo de RSC compuesto por cuatro dimensiones: la dimensión económica (generación de riquezas), la dimensión legal (respeto a las leyes sociales), la dimensión ética (hacer cosas correctas) y la dimensión filantrópica (mejorar la vida comunitaria) organizaciones suelen interesarse más a menudo por las responsabilidades económicas, cabe recordar que la gestión de dichas dimensiones debe realizarse desde una perspectiva equilibrada y global, favoreciendo la creación de un valor añadido a cada una de las responsabilidades en las organizaciones. (Adhepeau, 2013)

Analizando otra visión, presentada por la Confederación de la Producción y del Comercio y Prohumana (2006), referenciada por Díaz (2015) sugiere las dimensiones que deben considerarse en una empresa socialmente responsable:

Valores y coherencia: Comportamiento ético que debe tener una compañía y que delimita la manera de actuar de sus miembros y su relación con los diferentes grupos de interés a nivel externo.

Público interno: Desempeño de la empresa en relación con sus colaboradores, quienes tienen un lugar primordial en su gestión. Una compañía que quiera incrementar su productividad debe preocuparse por la satisfacción de sus empleados; Relación con proveedores: Relación directa con las empresas que proveen materias primas e insumos. La RS de una empresa es fundamental dentro de un encadenamiento productivo. La organización socialmente responsable debe desarrollar una política de relación estrecha con sus proveedores que genere confianza, lealtad, y transparencia;

Relación con consumidores: Comportamiento de una organización con sus consumidores y que puede variar las ventas de un producto o servicio e influir en su marca o sello. Las empresas deben forjar respeto con sus clientes para fomentar fidelidad y reputación corporativa; Relaciones con la comunidad: Políticas y procedimientos con relación a los públicos de interés y con los individuos de la comunidad. Las empresas deben establecer programas de inversión social, pues esto aumentará su ventaja comparativa y por ende la reputación corporativa;

Medioambiente: Prácticas, políticas, diseño e implementación de los sistemas de gestión ambiental que aseguren la sostenibilidad de la organización. Por tanto, las empresas no deben descuidar sus grupos de interés, pues ellos contribuyen al buen desempeño de las organizaciones; con base en lo antes preceptuado, y en vista de ser ésta la visión más completa en el tema de la RSE, será la que servirá de base para hacer el análisis de resultados de la presente investigación.

Como segundo punto de análisis, es de acotar que existe una teoría que tomó relevancia en temas sociales específicamente en lo referente a responsabilidad corporativa y es la expuesta por Frigant (2015), quien alude al tema de la siguiente manera: "la teoría de los participantes, las prácticas de RSE difieren de un área geográfica a otra y que, por otra parte, dentro de cada área geográfica, existen presiones sociales que crean incertidumbre". En otras palabras, con el fin de disminuir la inseguridad y ganar confianza las compañías suelen imitar lo que hacen otras compañías consideradas como competencia y referencias internacionales lo que a su vez permite adoptar una teoría de tipo institucional. A la teoría anterior se ponen en consideración tres enfoques (Homburg et al. 2013). (Figura 3) 


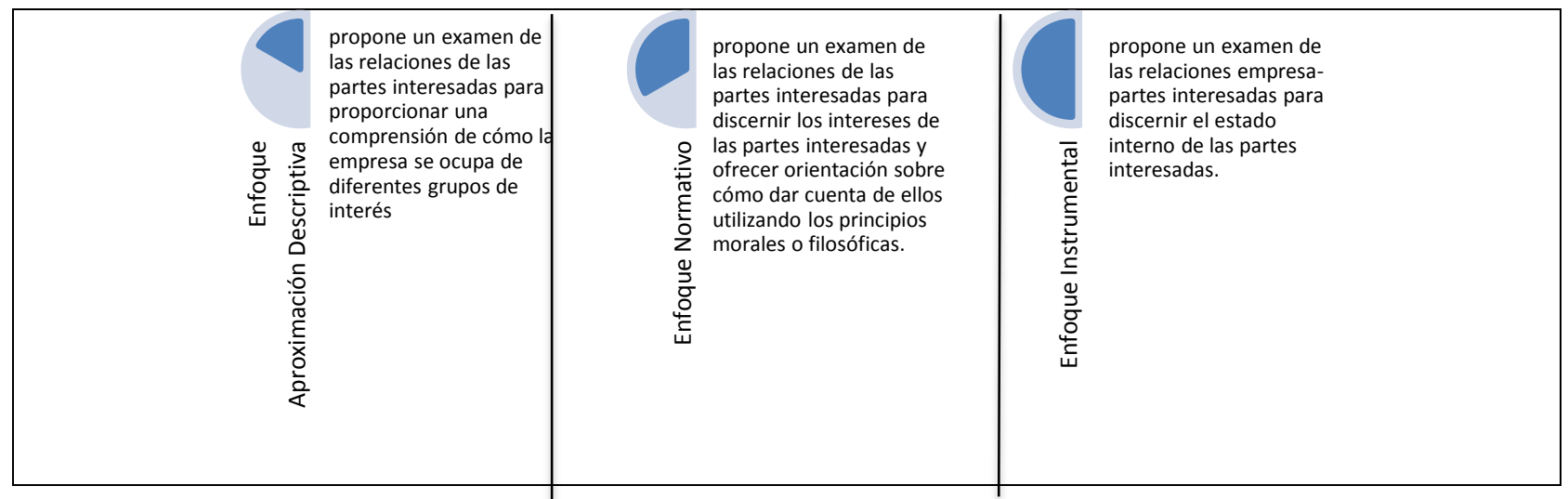

Fig.3: Enfoques de la teoría de los participantes (adaptada de Homburg et al., 2013)

\section{Resoluciones de responsabilidad social}

En la actualidad la responsabilidad social se ha vuelto parte elemental de las organizaciones, las cuales si no adoptan políticas y programas por su cuenta debida a la normatividad actual y entrante lo deben hacer sin excusa alguna, en este sentido Hirst (2017) mediante un estudio logra establecer las resoluciones primordiales en términos de responsabilidad social y medio ambiente. (Tabla 5)

Tabla 5: Temas de resoluciones ambientales y sociales (adaptada de Hirst, 2017)

\begin{tabular}{|l|l|}
\hline \multicolumn{1}{|c|}{ Tipo } & \multicolumn{1}{|c|}{ Tipo de Resolución } \\
\hline \multirow{4}{*}{ Sesoluciones } & Contribuciones políticasDisclosure \\
\cline { 2 - 3 } & Divulgación de presión política \\
\cline { 2 - 3 } & Actividades políticas y Acción \\
\cline { 2 - 3 } & $\begin{array}{l}\text { Derechos humanos } \\
\text { Evaluación de riesgos }\end{array}$ \\
\cline { 2 - 3 } Ambientales & Orientación sexual Política anti-sesgo \\
\cline { 2 - 3 } & Resolución antisocial \\
\hline Resoluciones & Emisiones de gases de efecto invernadero \\
\cline { 2 - 2 } & Informe sobre sostenibilidad \\
\cline { 2 - 2 } & Cambio climático \\
\cline { 2 - 2 } & Reciclaje \\
\cline { 2 - 2 } & Organismos genéticamente modificados \\
\hline
\end{tabular}

Así pues, es posible concluir que la responsabilidad social empresarial debe estar enfocada en primera medida para beneficio de los grupos de interés, en segundo lugar para beneficio de la misma organización y finalmente a darle valor comercial a la organización dado que independientemente de las normas del gobierno es una actividad provechosa para cada una de las partes. En términos de Bhattacharya y Sen (citados por Tsarenko y Tojib, 2015), "el objetivo de la RSE es reducir al mínimo los efectos externos negativos de una firma y maximizar los beneficios para la comunidad en general".

\section{METODOLOGÍA}

La presente investigación corresponde a la denominada cuantitativa la cual implica recolectar, procesar y estudiar datos cuantitativos sobre variables definidas con anterioridad, estos datos que se muestran en el informe final, están en total consonancia con las variables que se declararon desde el principio y los resultados obtenidos van a brindar una realidad específica a la que estos están sujetos, de tal manera que en este apartado se encontrarán el tipo y método de estudio, fuentes e instrumento de información, muestra, tratamiento y análisis de información.

Tipo de Estudio: A fin de llevar a cabo la presente investigación se utilizará el método Descriptivo- Explicativo, el cual sugiere la relación de variables, interpretadas por medio de las relaciones obtenidas en la recolección de información, mediante una sistematización y análisis de la misma. 
Método de Estudio: Según Méndez (2008), se tomará como fundamento el método denominado deductivo, para poder explicar algunos de los comportamientos y situaciones propias de los grupos de interés tomados como objeto de estudio en el presente artículo.

Fuentes e Instrumento de información: Para recolectar la información se utilizó una encuesta estructurada, adaptada teniendo en cuenta lineamientos sugeridos por el Instituto Argentino de Responsabilidad Social (2005), y la encuesta de Fenalco -Autodiagnóstico Consultores Empresariales (2008). Para las fuentes secundarias se acudió a estudios previos realizados en otras regiones de Colombia y del mundo. Además, se realizó la consulta de material documental sugerida para fuentes secundarias.

Tamaño de Muestra: Se tomó una muestra de 212 encuestas distribuidas en las 19 Pymes de actividad floricultora. El diseño muestral se hizo estratificado debido a la variabilidad en el tamaño de las empresas, manteniendo la proporcionalidad de las poblaciones. Debido a dificultades con respecto al acceso, se tomó solo una parte de los clientes internos.

Tratamiento y análisis de información: El tratamiento de la información se llevó a cabo discriminando las dimensiones expuestas por Díaz (2015), y su análisis descriptivo se hizo basado en el paquete SPSS V.24 y el programa EXCEL. En la Tabla 6 se muestran las generalidades del estudio y su aplicación

Tabla 6: Ficha técnica del Estudio

\begin{tabular}{|l|l|}
\hline \multicolumn{1}{|c|}{ Fecha de realización encuesta } & \multicolumn{1}{c|}{ Enero-Diciembre de 2017.} \\
\hline Institución & Universidad Pedagógica y Tecnológica de Colombia \\
\hline Facultad & Sede Sogamoso \\
\hline Escuela & Administración de Empresas \\
\hline Departamento & Boyacá \\
\hline Población & Microempresas del corredor industrial \\
\hline Tamaño de la población & 19 empresas \\
\hline Procedimiento de recolección & Estratificado por conveniencia \\
\hline Sistema de procesamiento & SPSS ${ }^{\text {TM }}$ (v. 24) y Excel \\
\hline Metodología & $\begin{array}{l}\text { Cuestionario escrito Instituto Argentino de Responsabilidad Social (2005), y la } \\
\text { encuesta de Fenalco -Autodiagnóstico Consultores Empresariales (2008) }\end{array}$ \\
\hline Unidad de análisis & Propietarios de las Microempresas y sus grupos de interés \\
\hline Realizador del estudio & Investigadores del proyecto \\
\hline Prueba piloto & Se aplicaron un total de 4 encuestas \\
\hline
\end{tabular}

Diagrama de proceso metodología propuesta: En la Figura 4 el diagrama del proceso de la investigación llevada a cabo, en el cual se resaltan las fases más importantes del proceso según Quivy y Campendhoudt (2005).

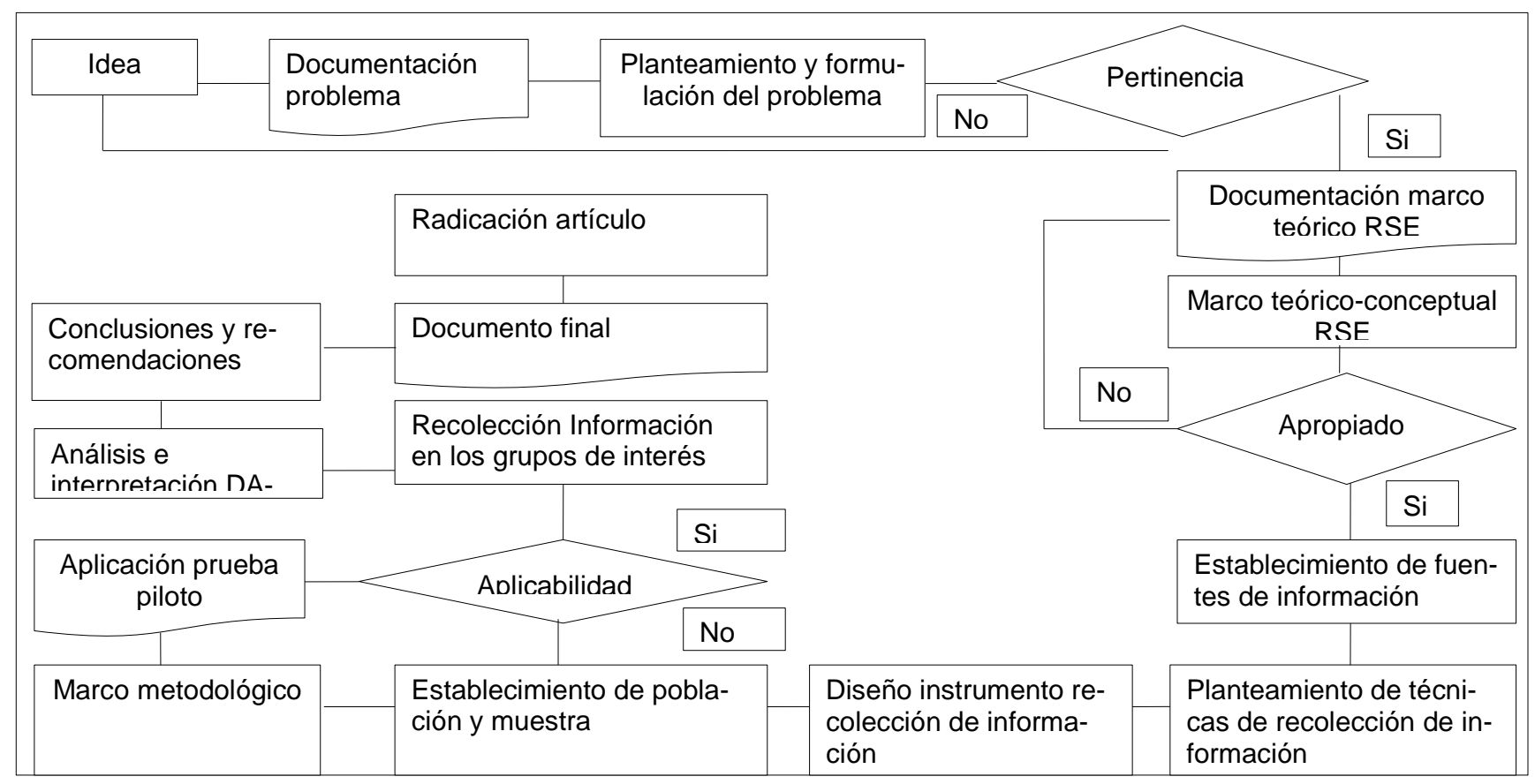

Fig. 4: Diagrama del proceso metodológico. 


\section{RESULTADOS Y DISCUSIÓN}

Se encontró que de las 19 empresas objeto de estudio, dos corresponden a medianas empresas y las restantes 17 corresponden a pequeñas empresas (Hernández y Sánchez, 2016). Para el análisis del estudio, éste se dividió en las dimensiones básicas de la RSE: Valores y Coherencia, Público Interno, Medioambiente, Relación con Proveedores, Relaciones con la Comunidad y Relación con Consumidores. De acuerdo a lo anterior y para facilitar la explicación al lector, se presentan las tablas resumen en valor absoluto de frecuencia y en porcentaje de las preguntas más relevantes del instrumento de recolección de información, así las cosas, se resaltaron los aspectos más relevantes de cada dimensión (con relación a Valores y Coherencia se evidencian en la Tabla explicada No 7; en lo referente a la dimensión medio Ambiente, aparecen la Tabla No 8; igualmente en lo concerniente a Público interno y la Relación con Proveedores se esgrime en la explicación de la Tabla No 9, para finalizar con la dimensión de Relaciones con Consumidores y la Comunidad abordadas en la Tabla 10, tal como a continuación se esgrimen. Con relación a la primer dimensión de Valores y coherencia, documentada en la Tabla 7, la primer pregunta apuntó a si la empresa posee un código de ética 0 conducta formal, donde el $55 \%$ de los encuestados manifestó conocer la existencia de éste y, aunque es un porcentaje favorable, debería ser superior.

Tabla 7: Variables analizadas en la dimensión de valores y coherencia

\begin{tabular}{|c|c|c|c|c|c|c|c|}
\hline \multicolumn{2}{|c|}{ Opciones de Respuesta } & $\begin{array}{c}\text { Totalmente en } \\
\text { desacuerdo }\end{array}$ & $\begin{array}{c}\text { Más en } \\
\text { desacuerdo } \\
\text { que en } \\
\text { acuerdo } \\
\end{array}$ & $\begin{array}{c}\text { Ni en } \\
\text { desacuerdo } \\
\text { ni en } \\
\text { acuerdo } \\
\end{array}$ & $\begin{array}{c}\text { Más de } \\
\text { acuerdo } \\
\text { que en } \\
\text { desacuerdo }\end{array}$ & $\begin{array}{l}\text { Totalmente } \\
\text { de acuerdo }\end{array}$ & Total \\
\hline \multirow{2}{*}{$\begin{array}{l}\text { Existencia } \\
\text { Código de ética }\end{array}$} & Frecuencia & 117 & 0 & 6 & 76 & 13 & 212 \\
\hline & Porcentaje & 55 & 0 & 3 & 36 & 6 & 100 \\
\hline \multirow{2}{*}{$\begin{array}{l}\text { Existencia } \\
\text { Prácticas } \\
\text { Ilegales }\end{array}$} & Frecuencia & 0 & 0 & 15 & 40 & 157 & 212 \\
\hline & Porcentaje & 0 & 0 & 7 & 19 & 74 & 100 \\
\hline \multirow{2}{*}{$\begin{array}{l}\text { Existencia de } \\
\text { políticas contra } \\
\text { acoso laboral }\end{array}$} & Frecuencia & 6 & 6 & 7 & 21 & 172 & 212 \\
\hline & Porcentaje & 3 & 3 & 3 & 10 & 81 & 100 \\
\hline \multirow{2}{*}{$\begin{array}{l}\text { La empresa } \\
\text { realiza estudios } \\
\text { en temas de } \\
\text { RSE }\end{array}$} & Frecuencia & 40 & 104 & 40 & 22 & 6 & 212 \\
\hline & Porcentaje & 19 & 49 & 19 & 10 & 3 & 100 \\
\hline \multirow{2}{*}{$\begin{array}{l}\text { Se comparte el } \\
\text { plan estratégico } \\
\text { a todos nivel }\end{array}$} & Frecuencia & 13 & 6 & 76 & 49 & 68 & 212 \\
\hline & Porcentaje & 6 & 3 & 36 & 23 & 32 & 100 \\
\hline
\end{tabular}

Es claro que los grupos de interés externos no conocen dicho documento, una segunda consulta indagó sobre la existencia de prácticas ilegales para la obtención de ventajas comerciales, revelando que el $74 \%$ no está de acuerdo, mientras que el $7 \%$ considera que dicha situación no es relevante, por eso no están ni de acuerdo, ni en desacuerdo. La tercera interrogación fue si la empresa posee políticas y/o procedimientos de control y sanción ante posibles situaciones de acoso, dando como resultado, que el $81 \%$ no está de acuerdo con estas prácticas y manifiestan que las entidades poseen sanciones coincidente con lo sugerido por Adhepeau (2013), por otro lado, el 3\% considera que existen dichas situaciones, pero que no son sancionadas, a pesar de existir hoy una tendencia de equidad de género y de que la mayoría de las labores del sector son desempeñadas por mujeres; con relación a la cuarta consulta, ésta se remitió a conocer sobre el apoyo brindado por especialistas a la organización para mejorar la resolución de dilemas éticos, socio ambientales y relativos a derechos humanos, en tal sentido, se encontró, que el $49 \%$ dio una respuesta negativa, lo que indica que dichas actividades no se llevan a cabo en las empresas floricultoras, y por ende, son reacias a las investigaciones y a la intervención del exoambiente (Carnahan et al. 2017). Para concluir, la quinta duda fue si a la gerencia se le presentan indicadores de gestión y si en la empresa se comparte el plan estratégico a todos los niveles de la organización, encontrándose que el $26 \%$ respondió de manera positiva, mientras que el $65 \%$ considera no estar enterado de esta situación, Igualmente, el 32\% manifestó que conoce y comparte el plan estratégico, lo cual podría deberse a que éste corresponda a la alta dirección dado el bajo nivel académico de los trabajadores y de mandos medios.

Con relación a la segunda parte (dimensión medio ambiente), tal como se observa en la Tabla 8, se inquirió en primer lugar sobre las políticas explícitas de no vinculación de menores en sus contratos con terceros, respondiendo contundentemente en un $71 \%$ que sí existen este tipo de políticas, a su vez, el $6 \%$ dijo que no existen estas medidas. Esto es coherente con la realidad, pues a través de observaciones pudo establecerse que el trabajo infantil no se presenta. Con relación a la segunda interrogación, se indagó sobre la concordancia de las operaciones de la empresa con los principios de la Organización Internacional del Trabajo (OIT), del 
pacto global y de las Metas del Milenio de la Organización de Naciones Unidas (ONU), al tenor de lo cual, el $81 \%$ de los grupos de interés enfatizó que no se cumple con estos requerimientos

Tabla 8: Variables analizadas en la dimensión medio ambiental

\begin{tabular}{|c|c|c|c|c|c|c|c|}
\hline \multicolumn{2}{|c|}{$\mathrm{Pregunta}_{\text {Presta }}$ Opciones de Respuesta } & \multirow{2}{*}{$\begin{array}{c}\text { Totalmente } \\
\text { en } \\
\text { desacuerdo }\end{array}$} & \multirow{2}{*}{$\begin{array}{c}\text { Más en } \\
\text { desacuerdo } \\
\text { que en } \\
\text { acuerdo } \\
\\
0\end{array}$} & \multirow{2}{*}{$\begin{array}{c}\text { Nien } \\
\text { desacuerdo } \\
\text { ni en } \\
\text { acuerdo } \\
\\
0\end{array}$} & \multirow{2}{*}{\begin{tabular}{|c}
$\begin{array}{c}\text { Más de } \\
\text { acuerdo que } \\
\text { en } \\
\text { desacuerdo }\end{array}$ \\
\\
76
\end{tabular}} & \multirow{2}{*}{$\begin{array}{c}\text { Totalmente } \\
\text { de acuerdo } \\
13\end{array}$} & \multirow{2}{*}{$\begin{array}{l}\text { Total } \\
212\end{array}$} \\
\hline $\begin{array}{lr}\text { La } & \text { empresa } \\
\text { contribuye } & \text { con } \\
\text { mejorías en ra } \\
\text { infraestructura o en el }\end{array}$ & Frecuencia & & & & & & \\
\hline $\begin{array}{l}\text { pueda la comunidad } \\
\text { disfrutar }\end{array}$ & Porcentaje & 58 & 0 & 0 & 36 & 6 & 100 \\
\hline \multirow{2}{*}{$\begin{array}{lr}\text { La empresa } & \text { tiene } \\
\text { indicadores } & \text { para } \\
\text { monitorear } & \text { los } \\
\text { impactos causados } \\
\text { por sus actividades en } \\
\text { la comunidad } & \text { de } \\
\text { entorno } & \end{array}$} & Frecuencia & 89 & 21 & 68 & 28 & 6 & 212 \\
\hline & Porcentaje & 42 & 10 & 32 & 13 & 3 & 100 \\
\hline \multirow{2}{*}{$\begin{array}{l}\text { En los últimos tres } \\
\text { años la empresa ha } \\
\text { recibido reclamos de } \\
\text { la comunidad por } \\
\text { diversas formas de } \\
\text { contaminación }\end{array}$} & Frecuencia & 172 & 6 & 15 & 13 & 6 & 212 \\
\hline & Porcentaje & 81 & 3 & 7 & 6 & 3 & 100 \\
\hline \multirow{2}{*}{$\begin{array}{l}\text { la empresa ofrece } \\
\text { Servicio de Atención al } \\
\text { Cliente (SAC) u otra } \\
\text { forma de atención } \\
\text { especializada }\end{array}$} & Frecuencia & 123 & 0 & 21 & 47 & 21 & 212 \\
\hline & Porcentaje & 58 & 0 & 10 & 22 & 10 & 100 \\
\hline \multirow{2}{*}{$\begin{array}{|lr|}\text { La empresa } & \text { tiene } \\
\text { implementado r un } \\
\text { procedimiento para } \\
\text { conocer el nivel de } \\
\text { satisfacción de sus } \\
\text { clientes } & \\
\end{array}$} & Frecuencia & 21 & 0 & 95 & 83 & 13 & 212 \\
\hline & Porcentaje & 10 & 0 & 45 & 39 & 6 & 100 \\
\hline \multirow{2}{*}{$\begin{array}{l}\text { La empresa evalúa } \\
\text { anualmente el número } \\
\text { de reclamaciones }\end{array}$} & Frecuencia & 151 & 21 & 21 & 13 & 6 & 212 \\
\hline & Porcentaje & 71 & 10 & 10 & 6 & 3 & 100 \\
\hline
\end{tabular}

Dicha situación permite esclarecer, que este tema ha sido un mito en el sector y se vislumbra como una realidad en temas de trabajo digno (Mohd et al. 2017), por su parte una minoría (6\%), manifestó que sí se están cumpliendo las normativas. Un tercer interrogante se orientó hacia la parte ambiental, donde el $42 \%$ manifestó no conocer la estrategia de la empresa en cuanto al desarrollo sostenible, en tanto que el $26 \%$ conoce los programas de gerenciamiento de residuos con participación del cliente y el $13 \%$ no tiene interés por el tema, de la misma forma, el 9\% desconoce si se aplican las políticas de monitoreo para aumentar la calidad ambiental de gestión de la organización concordante tangencialmente con el estudio en empresas brasileras hecho por Galego et al. (2014). Estos resultados muestran que lo ambiental es una política de RSE de poca importancia. Igualmente se encontró, que el $10 \%$ manifiesta desconocer los controles del impacto ambiental. Una tercera inquietud versó sobre la relación de las empresas con los clientes internos y la garantía del derecho de sindicalización, representación y negociación colectiva y también se preguntó en el cuarto interrogante sobre políticas y mecanismos formales para oír y acompañar posturas de los empleados, hallándose que el $68 \%$ declaró que no se garantiza la actividad sindical, así mismo, ningún entrevistado consideró que se poseen dichas representaciones. Para concluir este punto, la última inquietud se direccionó con los programas para mejorar la calidad de vida de los trabajadores, en donde más del $74 \%$ manifiesta que no hay políticas al respecto. 
En lo concerniente al análisis de la variable de público interno y la relación con proveedores presentada por la Tabla 9, esta se centró en la primera parte sobre la prevención de enfermedades del trabajo y de los programas de higiene y seguridad industrial, encontrándose, que el $84 \%$ dijo estar de acuerdo, mientras que el 6\% está en desacuerdo. En un segundo segmento, se buscó identificar el nivel de estabilidad emocional que la empresa promueve en los trabajadores para lograr relaciones armónicas en el trabajo y en el hogar, dando como resultado que el $52 \%$ de los encuestados se encuentra de acuerdo, en tanto que el $3 \%$ se encuentra en desacuerdo.

Tabla 9: Variables analizadas en la dimensión de público interno y relación con proveedores

\begin{tabular}{|c|c|c|c|c|c|c|c|}
\hline \multicolumn{2}{|c|}{$\overbrace{\text { Pregunta }}^{\text {Opciones de Respuesta }}$} & $\begin{array}{l}\text { Totalmente } \\
\text { en } \\
\text { desacuerdo }\end{array}$ & $\begin{array}{c}\text { Más en } \\
\text { desacuerdo } \\
\text { que en } \\
\text { acuerdo }\end{array}$ & $\begin{array}{c}\text { Ni en } \\
\text { desacuerdo } \\
\text { ni en acuerdo }\end{array}$ & $\begin{array}{c}\text { Más de } \\
\text { acuerdo que } \\
\text { en } \\
\text { desacuerdo }\end{array}$ & $\begin{array}{l}\text { Totalmente } \\
\text { de acuerdo }\end{array}$ & Total \\
\hline \multirow{2}{*}{$\begin{array}{l}\text { La empresa } \\
\text { posee un } \\
\text { programa de } \\
\text { prevención de } \\
\text { accidentes de } \\
\text { trabajo y } \\
\text { enfermedades } \\
\text { profesionales }\end{array}$} & Frecuencia & 13 & 0 & 21 & 0 & 178 & 212 \\
\hline & Porcentaje & 6 & 0 & 10 & 0 & 84 & 100 \\
\hline \multirow{2}{*}{$\begin{array}{l}\text { La empresa } \\
\text { promueve el } \\
\text { equilibrio entre la } \\
\text { vida laboral y la } \\
\text { vida familiar }\end{array}$} & Frecuencia & 7 & 13 & 21 & 61 & 110 & 212 \\
\hline & Porcentaje & 3 & 6 & 10 & 29 & 52 & 100 \\
\hline \multirow{2}{*}{$\begin{array}{l}\text { La empresa } \\
\text { tiene fiabilidad } \\
\text { de los } \\
\text { suministros de } \\
\text { materias primas } \\
\text { e insumos }\end{array}$} & Frecuencia & 6 & 28 & 82 & 83 & 13 & 212 \\
\hline & Porcentaje & 3 & 13 & 39 & 39 & 6 & 100 \\
\hline \multirow{2}{*}{$\begin{array}{l}\text { La empresa está } \\
\text { orientada a } \\
\text { conocer la } \\
\text { relación entre la } \\
\text { empresa y } \\
\text { nuevos } \\
\text { proveedores } \\
\text { para garantizar } \\
\text { una buena } \\
\text { relación }\end{array}$} & Frecuencia & 102 & 48 & 34 & 15 & 13 & 212 \\
\hline & Porcentaje & 48 & 23 & 16 & 7 & 6 & 100 \\
\hline \multirow{2}{*}{$\begin{array}{l}\text { La empresa } \\
\text { incluye a } \\
\text { individuos o } \\
\text { grupos de la } \\
\text { comunidad }\end{array}$} & Frecuencia & 6 & 13 & 21 & 123 & 49 & 212 \\
\hline & Porcentaje & 3 & 6 & 10 & 58 & 23 & 100 \\
\hline
\end{tabular}

Con relación a la tercera pregunta, esta se orientó sobre la relación con proveedores y el conocimiento de la empresa sobre el origen de las materias primas y la garantía de que en esos orígenes se respetan los derechos humanos y el medio ambiente, descubriendo que el 39\% dijo ser indiferentes a esta actividad, por otra parte, el 39\% afirmó que es necesario conocer la procedencia de los insumos. En lo atinente a la cuarta inquietud, ésta indagó sobre el interés de la empresa por conocer la política de responsabilidad social, a lo cual los investigados respondieron en un $48 \%$ no está de acuerdo, mientras que el $6 \%$ cree que la empresa sigue este protocolo. Igualmente la quinta pregunta se soportó en Homburg et al. (2013), versando sobre las relaciones con la inclusión de comunidades vulnerables, la vinculación de grupos de la comunidad, cooperativas, y asociaciones de barrio, dando como resultado, que en un $58 \%$ considera que se promueve el desarrollo de la comunidad y por tanto, el 23\% tiene la certeza de la existencia de esta inclusión.

Por último, la Tabla 10, muestra la cuarta parte de la investigación, da buena cuenta la dimensión de la comunidad y las relaciones con los consumidores, en donde se examinó en una primera parte, si la entidad establece medidas que contribuyan con el mejoramiento de la comunidad que rodea a la empresa, encontrándose que el $58 \%$ no conocen la implementación de dichas acciones, en tanto que el 36\% cree que 
este tipo de acciones sí se realiza, de la misma manera se quiso averiguar sobre las relaciones con la comunidad, en donde, el $42 \%$ desconocen la existencia de éstas, mientras que el $3 \%$ dijo conocerlas, una tercera inquietud se dirigió a investigar si en los últimos tres años la empresa ha recibido reclamos de la comunidad por diversas formas de contaminación, hallándose que el $81 \%$ dijo que no.

Tabla 10: Variables analizadas en la dimensión de Relaciones con la comunidad y los consumidores

\begin{tabular}{|c|c|c|c|c|c|c|c|}
\hline \multicolumn{2}{|c|}{$\mathrm{Preg}_{\text {Pregunta }}$ Opciones de Respuesta } & $\begin{array}{l}\text { Totalmente } \\
\text { en } \\
\text { desacuerdo }\end{array}$ & $\begin{array}{c}\text { Más en } \\
\text { desacuerdo } \\
\text { que en } \\
\text { acuerdo }\end{array}$ & $\begin{array}{c}\text { Ni en } \\
\text { desacuerdo } \\
\text { ni en } \\
\text { acuerdo }\end{array}$ & $\begin{array}{c}\text { Más de } \\
\text { acuerdo que } \\
\text { en } \\
\text { desacuerdo }\end{array}$ & $\begin{array}{l}\text { Totalmente } \\
\text { de acuerdo }\end{array}$ & Total \\
\hline \multirow{2}{*}{$\begin{array}{lr}\text { La } & \text { empresa } \\
\text { contribuye } & \text { con } \\
\text { mejorías en la } \\
\text { infraestructura o en el } \\
\text { ambiente local que } \\
\text { pueda la comunidad } \\
\text { disfrutar }\end{array}$} & Frecuencia & 123 & 0 & 0 & 76 & 13 & 212 \\
\hline & Porcentaje & 58 & 0 & 0 & 36 & 6 & 100 \\
\hline \multirow{2}{*}{$\begin{array}{lr}\text { La empresa } & \text { tiene } \\
\text { indicadores } & \text { para } \\
\text { monitorear } & \text { los } \\
\text { impactos causados } \\
\text { por sus actividades en } \\
\text { la comunidad de } \\
\text { entorno }\end{array}$} & Frecuencia & 89 & 21 & 68 & 28 & 6 & 212 \\
\hline & Porcentaje & 42 & 10 & 32 & 13 & 3 & 100 \\
\hline \multirow{2}{*}{$\begin{array}{l}\text { En los últimos tres } \\
\text { años la empresa ha } \\
\text { recibido reclamos de } \\
\text { la comunidad por } \\
\text { diversas formas de } \\
\text { contaminación }\end{array}$} & Frecuencia & 172 & 6 & 15 & 13 & 6 & 212 \\
\hline & Porcentaje & 81 & 3 & 7 & 6 & 3 & 100 \\
\hline \multirow{2}{*}{$\begin{array}{l}\text { la empresa ofrece } \\
\text { Servicio de Atención al } \\
\text { Cliente (SAC) u otra } \\
\text { forma de atención } \\
\text { especializada }\end{array}$} & Frecuencia & 123 & 0 & 21 & 47 & 21 & 212 \\
\hline & Porcentaje & 58 & 0 & 10 & 22 & 10 & 100 \\
\hline \multirow{2}{*}{$\begin{array}{lr}\text { La empresa } & \text { tiene } \\
\text { implementado } & \text { un } \\
\text { procedimiento para } \\
\text { conocer el nivel de } \\
\text { satisfacción de sus } \\
\text { clientes }\end{array}$} & Frecuencia & 21 & 0 & 95 & 83 & 13 & 212 \\
\hline & Porcentaje & 10 & 0 & 45 & 39 & 6 & 100 \\
\hline \multirow{2}{*}{$\begin{array}{l}\text { La empresa evalúa } \\
\text { anualmente el número } \\
\text { de reclamaciones }\end{array}$} & Frecuencia & 151 & 21 & 21 & 13 & 6 & 212 \\
\hline & Porcentaje & 71 & 10 & 10 & 6 & 3 & 100 \\
\hline
\end{tabular}

La cuarta pregunta indagó si la empresa ofrece Servicio de Atención al Cliente (SAC) u otra forma de atención especializada, descubriéndose que el $58 \%$ contestó que la empresa no lo ofrece (Caichun et al., 2018), por su parte, el 10\% respondió que conocen dichos mecanismo, seguidamente se interrogó lo relacionado con la implementación de procedimientos para conocer el nivel de satisfacción de sus clientes, ante lo cual los encuestados dijeron en un margen del $45 \%$ que estos le son indiferentes, un $6 \%$ está de acuerdo en que la empresa lo haga. Para concluir este acapite, se indagó si las reclamaciones de los consumidores son atendidas, donde el $71 \%$ manifestó que no, pero creen que sería importante hacerlo.

\section{CONCLUSIONES}

De acuerdo con la metodología empleada y los resultados encontrados, se puede concluir que: 1) En lo relacionado con la perspectiva de Valores y Coherencia, no todos los grupos de interés tienen conocimiento 
de la existencia de dicho documento; igualmente, en cuanto a las prácticas ilegales que puedan presentarse dentro de la organización como lo son el acoso laboral, acoso sexual, explotación infantil, entre otros, y las medidas que ésta implementa para su respectivo control, es relevante la postura que tienen los empleados, aunque es evidente la indiferencia que presentan estas organizaciones en temas de apoyo o asesoría externa para temas de derechos humamos, ambientales, y éticos; en lo referente a los planes estratégicos no se están teniendo en cuenta a las personas que ocupan los cargos medios, y tampoco se están dando a conocer a toda la organización. 2). En la categoría de Medioambiente, pudo establecerse que existe total indiferencia por parte de las empresas hacia este ítem, consecuentemente, tampoco existen medidas de control ni mitigación por los daños causados. 3.) Para el tercer aspecto, existen relaciones armónicas al interior de la organización pero es bajo el nivel de vinculación de grupos vulnerables que permitan desarrollar procesos de inclusión. En lo concerniente a la relación con Proveedores no existe interés por el conocimiento acerca de las prácticas de responsabilidad social que manejan los proveedores, no se sabe en realidad la procedencia de la materia prima y tampoco hay interés por conocer las relaciones con los nuevos proveedores. 4).De las relaciones con la Comunidad queda claro la inexistencia de políticas que permitan la inclusión de la comunidad en actividades de la empresa, en lo referente a la relación con los consumidores se concluye que hay total desinterés hacia la percepción de los clientes. 5). Como conclusión general puede decirse que las empresas de este sector aún presentan desconocimiento e interés por la adopción e implementación de prácticas de responsabilidad social que les permitan mejorar en aspectos de producción y relaciones con todos sus grupos de interés. Si bien es cierto en algunos aspectos las empresas se han esforzado por lograr un equilibrio, es evidente que esto no está encaminado hacia objetivos referentes a la responsabilidad social. Es importante sensibilizar a los involucrados para comenzar por incluir este tema en sus planes estratégicos, involucrando a todas sus partes interesadas para mejorar en muchos aspectos débiles en la actualidad.

\section{REFERENCIAS}

Abreu, J. L. y M. Badii, Análisis del Concepto de Responsabilidad Social Empresarial,Daena, International Journal of Good Conscience, 2(1), 54-70, Octubre 2006 - Marzo (2007)

Adhepeau, J. L. M., Corporate Social responsability (CSR) and the Stakeholders's Theory in the Oil Sector of Ivory Coast, Prisma Social, Revista de Ciencias Sociales, 3, 303-331 (2013)

Baraibar, E. y L. Luna, The Mediating Effect of Transparency in the Relationship Between Corporate Social Responsibility and Corporate Reputation, doi:10.7819/rbgn.v20i1.3600, Rev. Brasileira de Gestão de Negócios, 20(1), 5-21 (2013)

Caichun, C., X. Tiaojun y E. Francis, Is Social Responsibility for Firms Competing on Quantity Evolutionary Stable?,doi:10.3934/jimo.2017049, Journal of Industrial \& Management Optimization, 14(1), 325-347 (2018)

Carnahan, S., D. Kryscynskl y D. Olson, When Does Corporate Social Responsibility Reduce Employee Turnover? Evidence from Attorneys Before and after 9/11, doi:10.5465/amj.2015.0032, Academy Of Management Journal, 60(5), 1932-1962 (2017)

Carroll, A., Corporate Social Responsibility: Evolution of a Definitional Construct, Business and Society 38(3), 268-295 (1999)

Chang, Y., T. Chen y M. Shu, Corporate Social Responsibility, Corporate Performance, and Pay-Performance SensitivityEvidence from Shanghai Stock Exchange Social Responsibility Index, doi:10.1080/1540496X.2016.1273768, Emerging Markets Finance \& Trade, 54(5), 1183-1203 (2018)

Davidson, P. y R. Griffin, Management: Australia in a Global Context, Wiley, Brisbane. De George, R. T. 1999, Business Ethics, $5^{\text {th }}$ Ed., Prentice Hall, Upper Saddle River, N.J. (2000)

Davis, K., Five Propositions for Social Responsibility, Business Horizons, 19-24 (1975)

Díaz, Ä.J., Responsabilidad Social Empresarial en los Hoteles Cinco Estrellas de la Ciudad Cartagena- aso Hotel Almirante Cartagena Colombia BC Hoteles S.A., Tesis de Titulación, Dpto. Contaduría Pública, Corporación Universitaria Rafael Núñez, Cartagena - Colombia (2015)

Drucker, P., Managing For the Future, The 1990's and Beyond, Butterworth Heinemann, Oxford (2003)

Farooq, O., D.E. Rupp y M. Farooq, The Multiple Pathways Through Which Internal and External Corporate Social Responsibility Influence Organizational Identification and Multifoci Outcomes: The Moderating Role of Cultural and Social Orientations, doi:10.5465/amj.2014.0849, Academy Of Management Journal, 60(3), 954-985 (2017)

Fenalco, Encuesta de Autodiagnóstico en Responsabilidad Social Empresarial, Consultores empresariales, Bogotá D.C. (2008)

Fernández, L.V., M. Jara-Bertin y F.V. Pineaur, Social Responsability Practices, Corporate Reputation and Financial Performance, RAE Revista de Administração de Empresas, 55(3), 329-344 (2015)

Frigant, V., Beyond the Business Case and Sustainable Chain Management: Why Do We Need to Build a Theory of Interfirm Social Responsibility, Management (France), 18(3), 234-253 (2015)

García, J.M., C. de la Calle, M.C. Valbuena y T. de Dios, Toward Construct Validation of "Social Responsability of University Student" (SRUS), Bordón, Revista de Pedagogía, 68 (3), 41-58 (2016) 
Geva, A., Theree Models of Corporate Social Responsibility: Interrelationships between Theory, Research and Practice, Business and Society Review, 113 (1), 1-41 (2008)

Hernández, F. y J. P. Sánchez, Analysis of Effect of Corporate Social Responsibility in the Business Results of Micro, Small and Medium-Sized Enterprises (MSMEs), Journal Globalization, Competitiveness and Governability, 10(1), 110-123 (2016)

Hildebrand, D., Y. Demotta, S. Sen y A. Valenzuela, Consumer Responses to Corporate Social Responsibility (CSR) Contribution Type, Journal of Consumer Research, 44(4), 738-758 (2017)

Hirst, S., Social Responsibility Resolutions, Journal of Corporation Law, 43(2), 217-244 (2017)

Homburg, C., M. Stierl y T. Bornemann, Corporate Social Responsibility in Business-to-Business Markets: How Organizational Customers Account for Supplier Corporate Social Responsibility Engagement, J. Marketing, 77(6), 54-72 (2013)

Instituto Argentino de Responsabilidad Social (IARSE), Instrumento de medición de Responsabilidad social empresarial, Buenos Aires (2005)

ISO 26000, 15 de Enero de 2015, Guía de Responsabilidad Social, Norma Internacional ISO 26000 (2015)

Lanis, R. y G. Richardson, Outside Directors, Corporate Social Responsibility Performance, and Corporate Tax Aggressiveness: An Empirical Analysis, doi:10.1177/0148558X16654834, Journal Of Accounting, Auditing \& Finance, 33(2), 228-251 (2018)

López, A. y R. Contreras, El concepto Responsabilidad Social Empresarial desde diversos enfoques teóricos, Ide@sCONCYTEG, 5(58), 420-433 (2010)

McCarthy, L., Empowering Women through Corporate Social Responsibility: A Feminist Foucauldian Critique, doi:10.1017/beq.2017.28, Business Ethics Quarterly, 27(4), 603-631 (2017)

Méndez, C., Metodología, Guía para elaborar diseños de Investigación en ciencias económicas, contables y administrativas, $4^{\mathrm{a}}$ Ed., LIMUSA, México (2008)

Mishra, S. y S. B. Modi, Corporate Social Responsibility and Shareholder Wealth: The Role of Marketing Capability, doi:10.1509/jm.15.0013, Journal of Marketing, 80(1), 26-46 (2016)

Mohd, S., S. Mohd y J. Akhter, The Interrelationship Between Corporate Governance and Corporate Social Responsibility in Indian Companies, IUP Journal Of Corporate Governance, 16(4), 31-45 (2017)

Padilla, C.P., D.X. Arévalo, M.A. Bustamante y C.L. Vidal, Responsabilidad Social Empresarial y Desempeño Financiero en la Industria del Plástico en Ecuador, Información Tecnológica, 28(4), 93-102 (2017)

Palazzo, G. y J. Schrempf-Stirling, Upstream Corporate Social Responsibility: The Evolution from Contract Responsibility to Full Producer Responsibility, Business and Society, 55 (4), 491-527 (2016)

Peña Miranda, D. D., A. Serra Cantallops y R. D. Muñoz González, Global Proposal for a Business Classification According to Corporate Social Responsibility Practices, doi:10.19052/ed.3762, Equidad y Desarrollo, (27), 15-35 (2017)

Preuss, L., R. Barkemeyer y A. Glavas, Corporate Social Responsibility in Developing Country Multinationals: Identifying Company and Country-Level Influences, doi:10.1017/beq.2016.42, Business Ethics Quarterly, 26(3), $347-378$ (2016)

Quivy, R. y L. Campendhoudt, Manual de investigación en ciencias sociales, Limusa, México D.F. (2005)

Rodríguez, M., La Responsabilidad Social Empresarial y los consumidores, CIRIEC-España, Revista de Economía Pública, Social y Cooperativa, 53, 97-109 (2005)

Silva, F.P., L.S. De Freitas y G.A. Cândido, Corporate social performance and corporate social responsibility: An analysis of theoretical models of the decades 1970-2000, Espacios, 37(7) (2016)

Taquia, R., El Nuevo Paradigma del Interés Social en el Marco de la Responsabilidad Social de la Empresa, Vox Juris, (39), 1-17 (2006)

Tsarenko, Y. y D. Tojib, Consumers' Forgiveness after Brand Transgression: the Effect of the Firm's Corporate Social Responsibility and Response, doi:10.1080/0267257X.2015.1069373, Journal of Marketing Management, 31(17-18), 18511877 (2015)

Witkowska, J., Corporate Social Responsability: Selected Theoretical and Empirical Aspects. Comparative, Economic Research, 19(1), 27-43 (2016)

Wood, D.J., Corporate Social Performance Revisted, doi: 10.2307/258977, Academy of Management Review, 16 (4), 758 769 (1991) 
